\title{
Analytical Model for Predicting Response and Flexure-Shear Resistance of Composite Beams Combining Reinforced Ultrahigh Performance Fiber-Reinforced Concrete and Reinforced Concrete
}

\author{
Talayeh Noshiravani ${ }^{1}$ and Eugen Brühwiler ${ }^{2}$
}

\begin{abstract}
The addition of an external layer of reinforced ultrahigh performance fiber-reinforced concrete (R-UHPFRC) on top of reinforced concrete (RC) floor slabs and bridge decks is an emerging technique for strengthening RC structures. As an additional reinforcement, a layer of R-UHPFRC significantly increases the maximum resistance and deformation capacity of RC elements, thus creating a composite element that herein is referred to as RU-RC elements. This paper presents an elastic-plastic fictitious RU-RC composite hinge model for the damage caused by flexural and flexure-shear cracks in the RC element of the composite members. The model accounts for the nonlinear interaction of the two elements due to intermediate-crack-induced debonding (ICD) zone in the near-interface concrete. The model determines the force-deflection response and force in the RU-RC composite tension chord. Furthermore, the contribution of the R-UHPFRC element and the shear resistance envelope of the member are calculated. Comparison with available experimental results shows that the model can accurately predict the member response, resistance and failure mode. A simplified formulation for the shear resistance of the composite members is proposed. The models in this paper are needed for the design of the structural behavior of RC beams strengthened with R-UHPFRC. DOI: 10.1061/(ASCE)ST.1943-541X.0000902. @ 2014 American Society of Civil Engineers.
\end{abstract}

Author keywords: UHPFRC; Composite beam; Shear; Deformation capacity; Plastic hinge; Push-over analysis; Analysis and computation.

\section{Introduction}

Strain-hardening ultrahigh performance fiber-reinforced concrete (UHPFRC) belongs to the family of high-performance fiber reinforced cementitious composites (Stang and Li 2004). The material with a highly compact matrix and fine steel fibers has been developed to combine a quasi-impermeable behavior with a high strength and ductility under tension or compression. UHPFRC is primarily distinguished for its tensile behavior. In tension, the behavior of UHPFRC is divided into a linear elastic phase, a quasi-linear strain-hardening phase and a nonlinear strain-softening phase (Fig. 1).

A thin layer of UHPFRC reinforced with small-diameter steel reinforcing bars, referred to as R-UHPFRC, can be used as a protective flexural reinforcement on reinforced concrete (RC) members. This method is an emerging technique for the design, protection and strengthening of new or existing structures (Brühwiler and Denarié 2008). The combination of the R-UHPFRC and $\mathrm{RC}$ elements, by either in-situ casting or gluing prefabricated plates, creates composite members with an enhanced structural performance (Alaee and Karihaloo 2003; Habel et al. 2006;

\footnotetext{
${ }^{1}$ Project Engineer, Zilch + Müller Ingenieure GmbH, Erika - Mann Straße 63, 80636 Munich, Germany (corresponding author). E-mail: talayeh.noshiravani@a3.epfl.ch

${ }^{2}$ Full Professor, École Polytechnique Fédérale de Lausanne, GC B2 386 (Bâtiment GC), Station 18, CH-1015 Lausanne, Switzerland. E-mail: eugen .bruehwiler@epfl.ch

Note. This manuscript was submitted on March 6, 2012; approved on June 26, 2013; published online on June 28, 2013. Discussion period open until July 18, 2014; separate discussions must be submitted for individual papers. This paper is part of the Journal of Structural Engineering, (C) ASCE, ISSN 0733-9445/04014012(10)/\$25.00.
}

Noshiravani and Brühwiler 2013). As illustrated in Fig. 2(a), the $\mathrm{R}$-UHPFRC layer on an RC member acts as an additional reinforcement, increasing the member resistance. Henceforth, these composite members are referred to as RU-RC members.

For floor slabs and bridge decks, Habel et al. (2006) recommend an R-UHPFRC to RC height ratio between 10 percent and 20 percent and an R-UHPFRC layer thickness between 30 and $100 \mathrm{~mm}$ (1.81 and 3.94 in.). This recommendation optimizes the interaction between the two elements and their contribution to the member resistance and allows an economic use of UHPFRC. The design does not require any mechanical device or stirrups to connect the two elements. Closely spaced small-diameter steel reinforcing bars in R-UHPFRC layers are necessary for the in-plane continuity (Oesterlee 2010; Wuest 2007).

The response of RU-RC members depends on the bond between the two elements. In presence of high shear stresses and diagonal flexure-shear cracks [Fig. 2(b)], the prying stresses on the R-UHPFRC element at the flexure-shear crack mouth initiate intermediate-crack-induced debonding (ICD) between the elements prior to the maximum resistance (Noshiravani 2012). The ICD in the $\mathrm{RC}$ element is related to a mixed-mode fracture at the interface due to the tension and shear forces acting in the layer (Teng et al. 2003). As shown in Fig. 2(b), the ICD zone manifests itself as a series of flexural cracks that gradually soften this zone, allowing for the formation of hinges in the RU layer.

The structural response of RU-RC beams predominantly subjected to flexure can be modeled using a plastic flexural hinge where the deformations are concentrated (Alaee and Karihaloo 2003). The experiments by Noshiravani and Brühwiler (2013) show that members with flexure-shear hinges have a higher rotation capacity than those with flexural hinges. The added deformation is not always due to more smeared cracks but the opening of a 

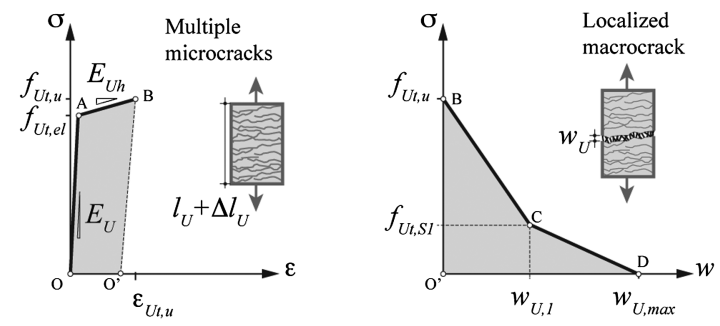

Fig. 1. Constitutive laws of UHPFRC in tension (adapted from Habel et al. 2006)

precursor flexure-shear crack initiating the development of the ICD zone, thus reducing the rotation constraint of the hinge. In a member with an inadequate shear resistance, the precursor crack becomes the collapse crack and limits the member rotation capacity.

Indeed, both the RC and the R-UHPFRC elements contribute to the shear resistance of RU-RC members $\left(V_{R U-R C}\right)$. The shear resistance of the RC element can be expressed as the sum of the contributions of concrete $\left(V_{c}\right)$ and steel $\left(V_{s}\right)$ along the flexure-shear collapse crack (Collins and Mitchell 1997). The contribution of the R-UHPFRC element $\left(V_{U}\right)$ to the member shear resistance is unknown. There is a need for an analytical model to predict the contribution of the R-UHPFRC layer to the resistance and deformation capacity of RU-RC beams.

This paper first describes a quasi-static elastic-plastic fictitious hinge model and the truss models for predicting the forcedeflection response of RU-RC beams subjected to combined bending and shear. It then presents the formulation for the flexureshear resistance of RU-RC beams with or without stirrups in terms of the member shear resistance versus deflection. The latter is a flexure-shear failure envelope for the beam response based on the hinge model. Lastly, it presents the validation of the model using the results of selected fracture tests on RU-RC cantilever beam specimens carried out by the authors (Noshiravani and Brühwiler 2013).

\section{Behavior of RU-RC Beams}

\section{RU-RC Composite Tension Chord}

In an RU-RC flexural member such as the one in Fig. 2(b), the tension force due to the negative moment is carried by the UHPFRC, its steel reinforcing bars and the top steel reinforcing bars in the RC section. The steel and UHPFRC reinforcements and part of the concrete interacting with them make up the RU-RC composite tension chord (Noshiravani 2012), analogous to the original tension chord model (Marti et al. 1998). The force in the RU-RC tension chord $\left(T_{R U-R C}\right)$ depends on bond conditions that define the interaction between the three materials in tension.

The bond between UHPFRC and concrete $\left(\tau_{U C}\right)$ is stronger than the tensile strength of concrete at the level of the RC tensile reinforcing bars below the interface; thus, the section can be assumed to be monolithic (Habel et al. 2006). The development of the ICD zone interferes with the bond between UHPFRC and concrete (Noshiravani 2012).

\section{States of Cracking in $R U-R C$ Beams}

Tests by the authors on the cantilever beams show that, similar to RC members, the cracking behavior of RU-RC members among others depends on the shear-span to depth ratio, the ratio of longitudinal reinforcement, the transverse reinforcement ratio, and the stirrup spacing $(s)$. In these tests the concrete and R-UHPFRC mixes are constant. The effects of cement quality, aggregate size, and fiber length are not included in the study. Furthermore, the static height of RC elements (with or without an R-UHPFRC layer) are constant. The thickness of the R-UHPFRC layer was chosen according to the recommended height ratio of R-UHPFRC to RC that is used in strengthening applications. The thickness of the layer as well as direction of pouring of the UHPFRC was similar to that of the tensile specimens for determining the material properties. These specimens were cut out of a larger slab; thus, the walleffect of specimen molds on the fiber direction was eliminated (Noshiravani 2012).

RU-RC members can be divided into different regions based on the states of cracking in the RC member. Fig. 3 shows how the kinematic state of the RU-RC beam unfolds as the force increases from $V_{k}$ to $V_{k+1}$. The force $V_{k}$ refers to the force when the precursor flexure-shear crack initiates and the ICD begins, i.e., $V_{k}=V_{\text {ICD }}$.

Three states are distinguished: State I is the monolithicuncracked state; State II is the monolithic-cracked state; and State III is the two-layer-cracked state. In State I, concrete is uncracked while UHPFRC may be in strain hardening. State II begins with the appearance of the flexural cracks and continues until the formation of the discrete precursor flexure-shear crack. Following the formation of the long flexure-shear crack, the ICD zone develops as a series of short cracks that appear as flexural cracks and rotate toward the long flexure-shear crack. The beam along the ICD

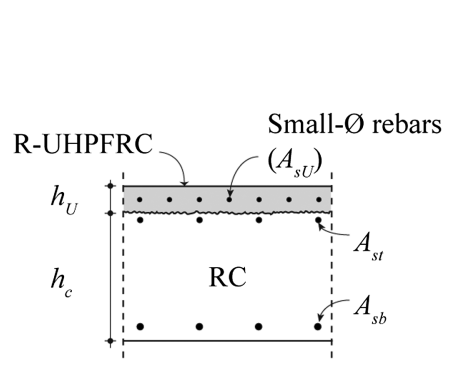

(a)

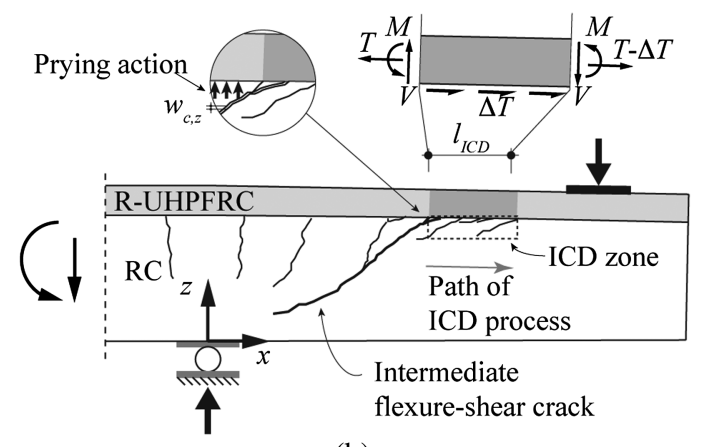

(b)

Fig. 2. (a) Cross section of an RU-RC slab strip cross section; (b) diagonal-intermediate-crack-induced debonding (ICD) 


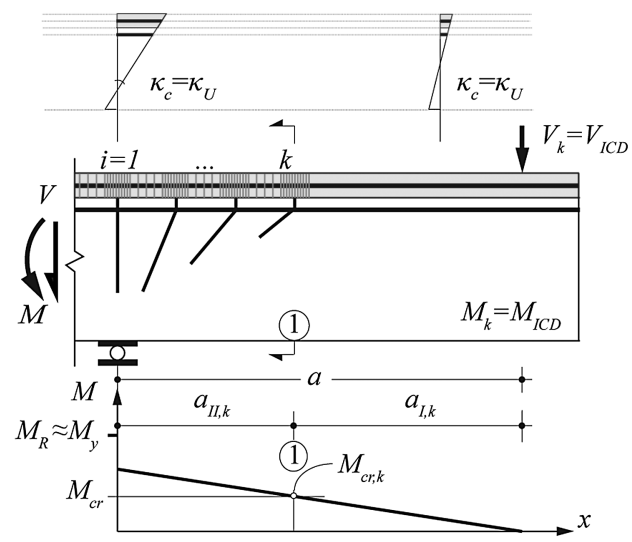

(a)

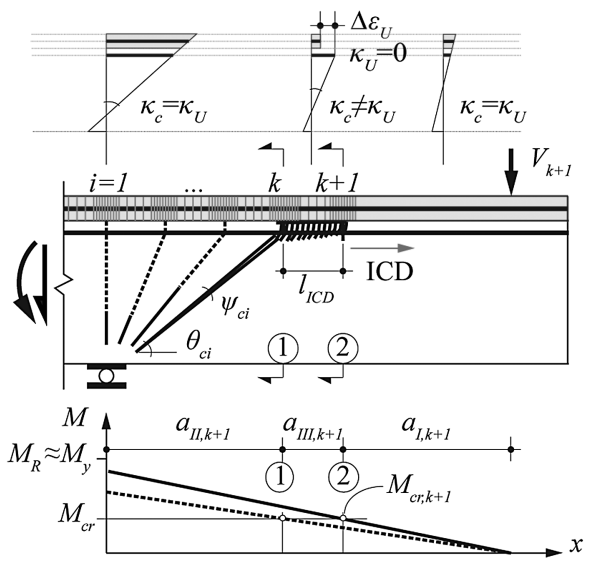

(b)

Fig. 3. Kinematic development of RU-RC beam between two load steps

zone is in State III. The cantilever span $(a)$ divisions at each state are respectively $a_{\mathrm{I}}, a_{\mathrm{II}}$, and $a_{\mathrm{III}}$.

Fig. 3 shows the strain profile of the beam at each state. The Euler-Bernoulli beam theory holds for the monolithic member prior to the ICD (Habel et al. 2006; Oesterlee 2010). In State III, the composite element is assumed to be a two-layer EulerBernoulli beam with an interlayer slip. For the UHPFRC layer under combined tension and bending, the slip $\Delta \varepsilon_{U}$ is defined as the difference between the average UHPFRC strain and the concrete strain at the interface due to the slip between the R-UHPFRC and $\mathrm{RC}$ elements.

The length of the regions in various states can be determined from the applied moment diagram (Fig. 3). The states are distinguished using the limits of cracking moment $M_{c r}$ and the precursor flexure-shear crack prior to the formation of the ICD zone at $M_{\mathrm{ICD}}$, i.e., $M_{k}$ in Fig. 3. $M_{c r}$ is determined from a sectional analysis, explicitly considering the UHPFRC strain-hardening behavior. $M_{\text {ICD }}$ is a function of $V_{\mathrm{ICD}}$ that is estimated using truss models, stress field models or numerical analysis (Noshiravani 2012).

\section{Truss Models for RU-RC Members}

The internal flow of forces in RU-RC members and the average force along the tension chord can be calculated using truss models or stress fields (Schlaich et al. 1987; Muttoni and Schwartz 1991). In members without transverse reinforcement, the transverse stress field is implicitly carried by concrete tension members (Muttoni and Schwartz 1991; Schlaich et al. 1987; Specht and Scholz 1995). Special truss models can also be used to account for specific mechanisms, e.g., dowel action is modeled using specific tension members that also resist bending stresses (Muttoni and Schwartz 1991).

The models in Fig. 4 describe the internal flow of forces in RU-RC beams before and after the development of the ICD zone. The truss model in Fig. 4(a) is a solution describing the beam action carrying the stresses in the member (Kani 1966). In Fig. 4(b), the flexure-shear crack interferes with the diagonal tension stress field close to the support. The elbow-shaped mechanism forms so that stresses circumvent the flexure-shear crack tip (Muttoni 2008).

The model in Fig. 4(a) may be used to estimate the force initiating State III, namely $V_{\text {ICD }}$. Eq. (1) estimates $V_{\text {ICD }}$ as the vertical component of the tension force in concrete between two flexural cracks at an average spacing of $s_{m}$ :

$$
V_{\mathrm{ICD}}=f_{c t} \cdot b \cdot s_{m} \cdot \sin \left(\zeta_{c r}\right)
$$

where $f_{c t}$ is the average tensile strength of concrete; $b$ is the width of the beam; and $\zeta_{c r}$ is the angle of the compression strut [Fig. 4(a)] that causes the diagonal crack. The calculated force based on Eq. (1) is in good agreement with the available test results (Noshiravani 2012).

Along the ICD zone, the R-UHPFRC element acts as a tensile membrane and a bending plate element transferring the vertical force corresponding to the compression member in State II to the hanger. It is assumed that there is no shear stress transfer between the concrete and the UHPFRC or steel reinforcing bars. Thus, $T_{R U-R C}$ along the ICD zone is constant.

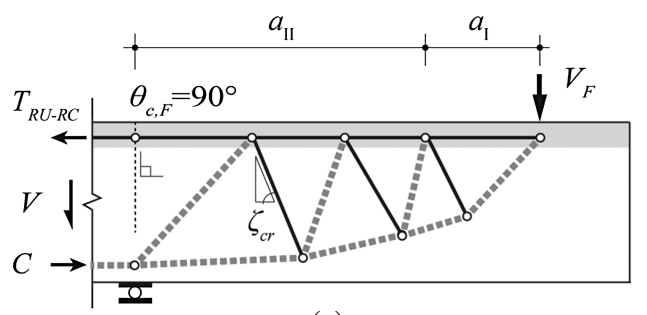

(a)
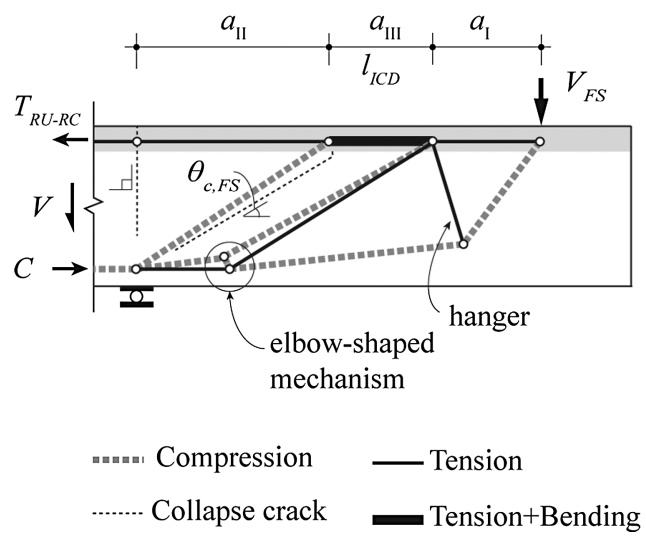

(b)

Fig. 4. Truss models of RU-RC beams prior to their (a) flexural; (b) flexure-shear failures 


\section{Fictitious Composite Hinge Model}

\section{Hinges in the RU-RC Member}

A series of flexural or flexure-shear cracks in the cracked region (Fig. 3) of a beam are referred to as a flexural or flexure-shear hinge, respectively (Bachmann 1967; Dilger 1966). The principal difference between the two hinge types is the orientation of the cracks in an $\mathrm{RC}$ element. An RC hinge relates the element rotation to the cumulative sum of the crack openings in a cracked region of a member. A plastic hinge forms upon the localization of the deformations at one crack, at which the reinforcing bars plastify. Fig. 5 illustrates the model of a flexure-shear hinge in the beam represented in Figs. 3 and 4.

The member rotation is the result of the opening of the hinge $(\psi)$, which is the sum of the rotations at each individual crack $\left(\psi_{i}\right)$ as a function of concrete crack opening $\left(w_{c}\right)$ and crack length $\left(l_{c r}\right)$. Eq. (2) estimates the rotation without considering the vertical component of the crack width (Bachmann 1967; Sigrist 1995), where $w_{c i, x}$ is the horizontal component of a concrete crack width, and $d_{s t}$ and $c$ are the location of the RC's tensile reinforcing bars and the height of the neutral axis, both measured from the extreme concrete compressive fiber:

$$
\psi_{i}=\frac{w_{c}}{l_{c r}} \cong \frac{w_{c i, x}}{d_{s t}-c}
$$

Assuming a linear average strain profile of the RC element in the hinge, the average hinge curvature $\left(\kappa_{m}\right)$ and compressive strain at the extreme concrete fiber $\left(\varepsilon_{c m}\right)$ as functions of the average strain of the tensile steel reinforcement in the RC section $\left(\varepsilon_{s m}\right)$ are:

$$
\kappa_{m}=\frac{\varepsilon_{s m}}{d_{s t}-c}
$$

and

$$
\varepsilon_{c m}=c\left(\frac{\varepsilon_{s m}}{d_{s t}-c}\right)
$$

The strain in the UHPFRC depends on the bond condition between the two elements. Prior to ICD, the curvatures of the two elements are assumed equal $\left(\kappa_{m}=\kappa_{U}=\kappa_{c}\right)$; however, with the separation of the two, $\kappa_{U}$ is assumed to be equal to zero [Fig. 3(a)]. Due to the strong bond between the UHPFRC and its reinforcing bars, their average strain at the neutral axis of the reinforcing bars is assumed to be equal. For an element with the reinforcing bars at the midheight of the R-UHPFRC section, Eq. (5) calculates the average strains of UHPFRC $\left(\varepsilon_{U m}\right)$ and its steel reinforcing bars $\left(\varepsilon_{\text {sUm }}\right)$ in a composite hinge:

$$
\varepsilon_{U m}=\varepsilon_{s U m}=\frac{\left(h_{U} / 2+h_{c}-c\right)}{c} \varepsilon_{c m}+\Delta \varepsilon_{U}
$$

Following the plastification of the steel reinforcing bars at a crack, the movement of the rigid bodies divided by the cracks is no longer contained. The rotation of a plastic hinge $\left(\psi_{P}\right)$ can be divided into its flexure and shear components (Dilger 1966). By accounting for the varying bond condition between the adjacent cracks in concrete and the longitudinal concrete strains at the crack tips, it is possible to consider the failure of the hinge due to the rupture of steel reinforcing bars, the crushing of concrete in flexure or the web crushing close to the tip of a flexure-shear crack (Bachmann 1967). $\psi_{P}$ is equal to the difference between the total rotation and the rotation of the beam at the onset of yielding.
In RU-RC beams, the total strain of the UHPFRC in the vicinity of a macro-crack in a plastic hinge is:

$$
\varepsilon_{U}^{\prime}=\frac{w_{U}}{2 h_{U}}
$$

\section{Hinge Length and RU-RC Tension Chord Strain Distribution}

The tension force acting in a hinge depends on the distribution of the tensile deformations in the RU-RC composite tension chord. The concept of a hinge length $\left(l_{h}\right)$ is used to relate the average strains to the deformations and crack opening in the hinge (Fig. 5). The hinge length varies between the elastic and plastic regimes. In the elastic regime, the hinge length $\left(l_{h, e l}\right)$ varies with the appearance of the different states along the beam. In the plastic regime, the hinge length reduces to the length of the plastic hinge $\left(l_{h, p l}\right)$.

In States I and II, the length of the monolithic hinge includes both the regions, thus $l_{h, e l}$ equals $a$. As State III begins to form, the composite tension chord divides into a two-layer chord. The slip between the components of the chord in State III causes the strains in the R-UHPFRC element to be less than that of the steel reinforcing bars in the $\mathrm{RC}$ element. Different hinge lengths can be used to calculate theses strains. It is assumed that with the formation of the flexure-shear crack the hinge length of the tensile reinforcing bars in the RC element $\left(l_{h, e l, s t}\right)$ becomes fixed, i.e., $l_{h, e l, s t}=a_{I I}$. Meanwhile, the hinge length of the R-UHPFRC element $\left(l_{h, e l, U}\right)$ continues to grow with the ICD zone, i.e., $l_{h, e l, U}=a_{\mathrm{II}}+a_{\mathrm{III}}$. To account for the losses at the anchorage, the anchorage length of each type of reinforcement is added to the length of the elastic hinge. The maximum anchorage length is assumed to be equal to the average crack spacing in concrete.

In the plastic hinge, the deformations concentrate at the location where the steel reinforcing bars plastify, in the vicinity of the dominant crack. Experimental evidence shows that with the softening of the UHPFRC and yielding of the steel reinforcing bars, the near-interface concrete cracks due to the geometrical incompatibility between the elements cause limited debonding of the elements in the composite tension chord (Habel et al. 2006; Oesterlee 2010). The debonding in State II is interrupted by the adjacent flexural cracks in concrete along the tension chord. As a result, the R-UHPFRC hinge length increases. It is assumed that

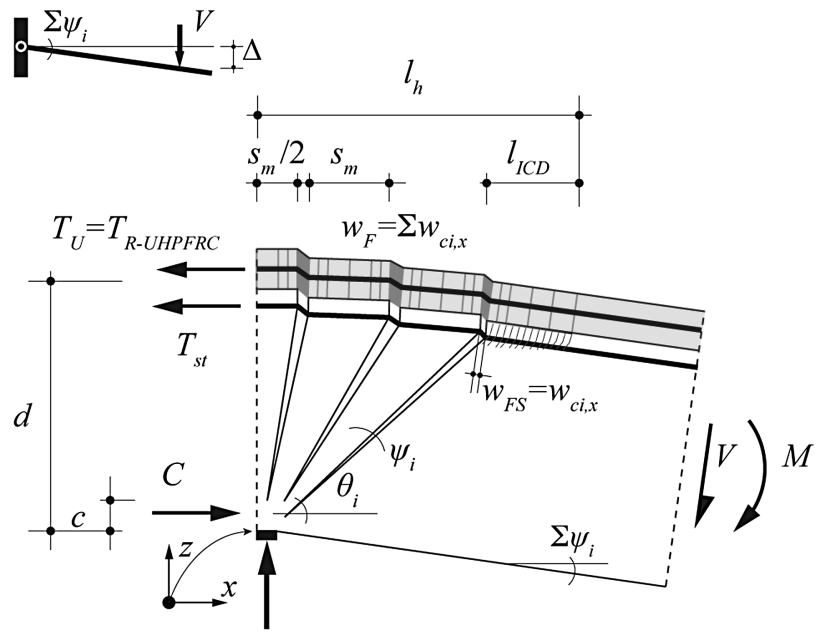

Fig. 5. RU-RC composite hinge adapted from Bachmann (1967) 
$l_{h, p l, s t}$ is equal to the length of the disturbed region at a crack, which is less than a distance equal to $h_{c}$ measured from the crack centerline. $l_{h, p l, U}$ is assumed to increase with the ICD zone in State III. Checking of the compatibility of the deformation of the two layers was done during the tests using the deflection and crack opening measurements of each element and the ICD zone (Noshiravani 2012).

To calculate the change of force along the RU-RC tension chord, the strain distribution along the hinge lengths needs to be determined. It is assumed that the hinge length along $a_{\mathrm{II}}$ is divided between the sum of the flexural crack widths $\left(w_{F}\right)$ and the opening of the discrete flexure-shear crack $\left(w_{F S}\right)$, indicated in Fig. 5. However, the strains in the R-UHPFRC element along $a_{\mathrm{III}}$ are due to the opening of the flexure-shear crack only. Thus, the average force in the $\mathrm{RC}$ reinforcing bars is constant, whereas the average force in the R-UHPFRC element decreases between $a_{\mathrm{II}}$ and $a_{\mathrm{III}}$. This reduction is the effect of the ICD and is directly related to the shear force in the R-UHPFRC layer.

\section{Force-Deflection Response}

The fictitious composite hinge $(\mathrm{FCH})$ model is developed to calculate the force-deflection response of RU-RC members both up to their maximum bending resistance and beyond yielding. Depending on the crack pattern, the model assumes that the rotation is due to the opening of one flexural hinge ( $\mathrm{F}$ hinge) or a flexureshear hinge (FS hinge). Fig. 6 shows the procedure for using the FCH model for calculating the force as a function of a given deflection for the force-deflection diagram of RU-RC beams with a flexure or a flexure-shear hinge. The model can predict the member response, beyond the softening of UHPFRC, up to the rupture of the steel longitudinal bars or crushing of concrete, i.e., up to a flexural failure. Collapse mechanisms are used to evaluate the member flexure-shear resistance.

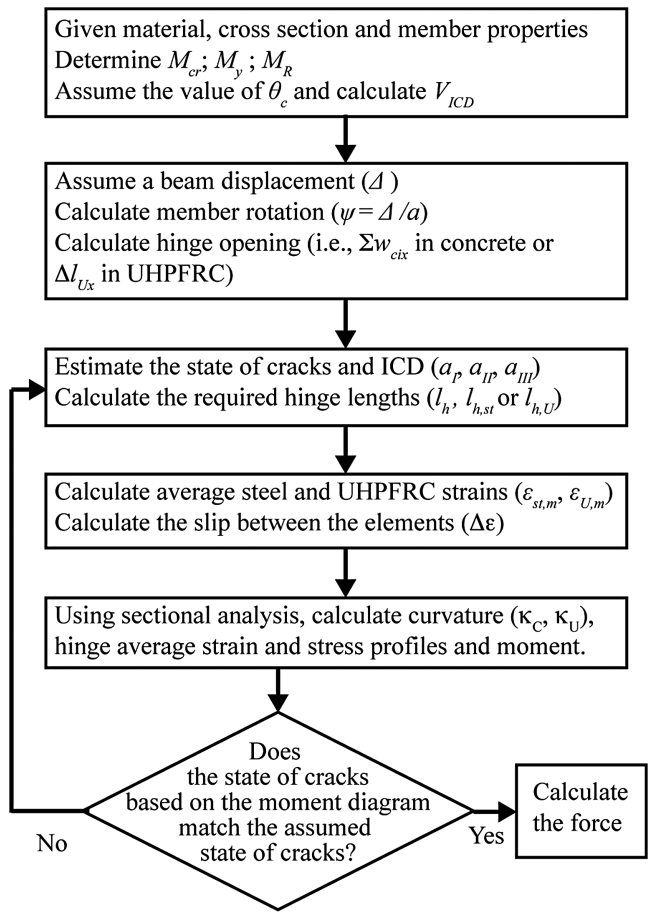

Fig. 6. Calculation flowchart of the force-deflection response of RU-RC beams

\section{Flexure-Shear Resistance}

\section{Flexure-Shear Collapse Mechanism}

Depending on the presence and magnitude of shear forces, RU-RC beam failure may be at a flexure-shear collapse crack. While a flexural failure occurs at the peak tensile resistance of the R-UHPFRC element, a flexure-shear failure is due to the crushing of concrete carrying the inclined compression stress field ahead of a diagonal crack.

Fig. 7 illustrates the flexure-shear collapse mechanism of an RU-RC beam. The figure includes the proposed double hinge mechanism in the R-UHPFRC element to model its bending in double curvature as it follows the movement of the divided RC rigid bodies. The resistance of the member depends on the contribution of each component to carrying the shear forces in the member. As illustrated in Fig. 7, upstream from the ICD at the mouth of a flexure-shear collapse crack is where the UHPFRC softens first. This is the location of a fixed hinge. The second hinge forms at the forefront of the ICD and remains in strain hardening until it reaches a fixed position, e.g., at a point load or where the applied moment equals zero.

Eq. (7) calculates the rotation of each R-UHPFRC hinge $\left(\psi_{U, i}\right)$ as a function of the displacement of the R-UHPFRC element $\left(\Delta_{U 1}\right.$ and $\left.\Delta_{U 2}\right)$ at two ends of the ICD zone $\left(a_{\mathrm{III}}\right)$, the beam rotation $(\psi)$ or the maximum deflection $(\Delta)$ of the cantilever span $(a)$, where $\Delta=\psi \cdot a$. In this equation, $\Delta_{U 1}$ is assumed to be equal to zero:

$$
\psi_{U, i}=\frac{\Delta_{U 2}-\Delta_{U 1}}{a_{\mathrm{III}}}=\frac{\left(a-a_{1}\right)}{a_{\mathrm{III}} \cdot a} \Delta=\frac{\left(a-a_{1}\right)}{a_{\mathrm{III}}} \psi
$$

The R-UHPFRC hinge is similar to a reinforced or fiber reinforced hinges with distributed reinforcement along its height (Marti et al. 1999; Casanova and Rossi 1997). The maximum length of the hinge is assumed as twice the height of the R-UHPFRC element $\left(h_{U}\right)$. The average curvature is approximately:

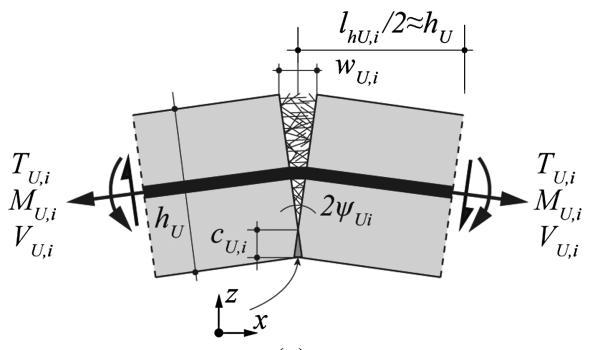

(a)

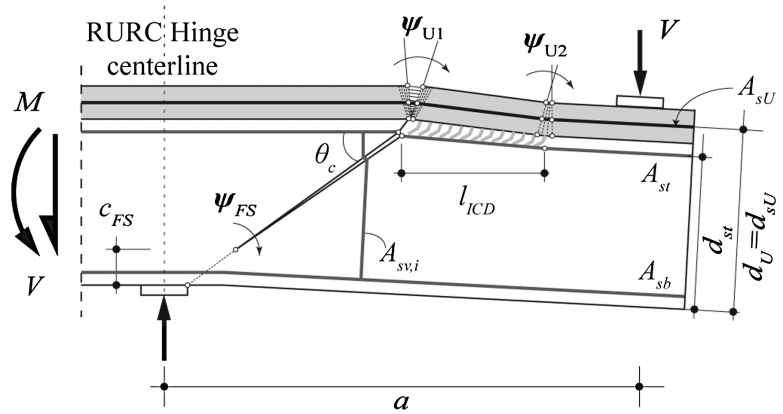

(b)

Fig. 7. (a) R-UHPFRC hinge; (b) flexure-shear crack defining the member failure (adapted from Noshiravani 2012) 


$$
\kappa_{U h} \cong \frac{\varepsilon_{U m h}}{h_{U}}
$$

\section{Contribution of the Constituent Materials}

In this section the shear resistance of RU-RC beams $\left(V_{R U-R C}\right)$ is calculated using the upper bound method. Eq. (9) calculates the shear resistance as the superposition of the contributions of concrete $\left(V_{c}\right)$, steel in concrete $\left(V_{s}\right)$, and the R-UHPFRC element $\left(V_{U}\right)$ :

$$
V_{R U-R C}=V_{c}+V_{s}+V_{U}
$$

The contribution of concrete is twofold. First, concrete carries the inclined compressive stresses ahead of the crack tip. Second, it contributes through aggregate interlock along the crack faces that depends both on the quality of cement and that of the aggregate. As shown by Stoffel (2000), the energy dissipated by concrete in crushing is much higher than that of the aggregate interlock. For flexure-shear crack openings in the RC element observed in tests on RU-RC beams, the concrete aggregate interlock is negligible. Eq. (10) provides an upper bound solution for the contribution of concrete crushing in front of the tip of a flexure-shear crack an angle of $\theta_{c}$ from a horizontal axis (Noshiravani 2012):

$$
V_{c}=\frac{f_{c e} \cdot b \cdot c_{F S}(\psi)}{2 \sin \left(\theta_{c}\right)}(1-\sin \alpha)
$$

This solution is adapted from the graphical solution based on the theory of plasticity for a translational web-crushing collapse mechanism (Stoffel 2000). In Eq. (10), the displacement vector $\alpha$ is measured from the failure plane, namely the collapse crack. It is assumed that the relative displacement between the $\mathrm{RC}$ bodies caused by the crushing is vertical, thus $\alpha+\theta_{c}=90^{\circ} ; f_{c e}$ is the effective strength of concrete in crushing; $b$ is the width of the beam; and $c_{F S}$ is the depth of the neutral axis at the centerline of the RU-RC hinge, which is a function of the hinge rotation $\psi$ (Fig. 7).

By bending in double curvature, the R-UHPFRC element provides an alternative mechanism for carrying the shear stresses. Eq. (11) calculates the shear force carried by the R-UHPFRC layer as a function of the hinge rotation:

$$
V_{U}\left(\psi_{U}\right)=\frac{2 M_{U}\left(T_{U}, \psi_{U}\right)}{l_{\mathrm{ICD}}\left(\psi_{U}\right)}
$$

where $M_{U}$ is the moment in the R-UHPFRC hinges. The rotation of the R-UHPFRC hinge is related to the RU-RC member rotation $\psi$ that generates the tensile stresses in the R-UHPFRC. The maximum shear resistance of the layer $\left(V_{U, \max }\right)$ is directly related to the maximum bending moment $\left(M_{U, R}\right)$ and inversely related to $l_{\mathrm{ICD}}$. Without a fixed support across a short span, it is impossible for the thin R-UHPFRC layer to fail in shear, i.e., in tension across a diagonal plane at an angle of $45^{\circ}$ from the longitudinal axis (SETRA and AFGC 2002; Ng et al. 2012). To calculate the tension along the R-UHPFRC layer in double curvature with the FCH model (Fig. 6), it is assumed that the constant tension is primarily the result of $w_{F S}$ and that the deformation due to this crack opening is distributed along $l_{\mathrm{ICD}}+2 h_{U}$. The tensile force in R-UHPFRC element is carried by both the steel and the UHPFRC in tension.

The main contribution of steel in concrete is due to the stirrups. The force in the stirrups increases with the opening of the flexureshear crack until they begin to yield. Eq. (12) expresses the force in the stirrups, where $A_{v}$ is the area of the stirrups crossing the crack and $\sigma_{s}$ is the stirrup stress as a function of the member rotation $(\psi)$ (Stoffel 2000):

$$
V_{s}=A_{v} \cdot \sigma_{s}(\psi)
$$

\section{Model Validation}

\section{Experiments}

For corroboration, the FCH model was used to determine the forcedeflection response of six selected specimens from an experimental campaign on cantilever RU-RC beams (Noshiravani and Brühwiler 2013). These include two reference RC beams (named L0 and MW0), one UHPFRC-RC composite beam (named L1), and three RU-RC beams with ribbed reinforcing bars (named L2, L3, and MW4). The test specimens are representative of RU-RC members used in structural applications. Fig. 8 provides the static system, dimensions, cross section, and reinforcement detailing of each specimen. The specimens are grouped according to the length of the cantilever spans. The beams with a shorter cantilever span carry a higher shear force. In Fig. 8, the specimen name is followed by

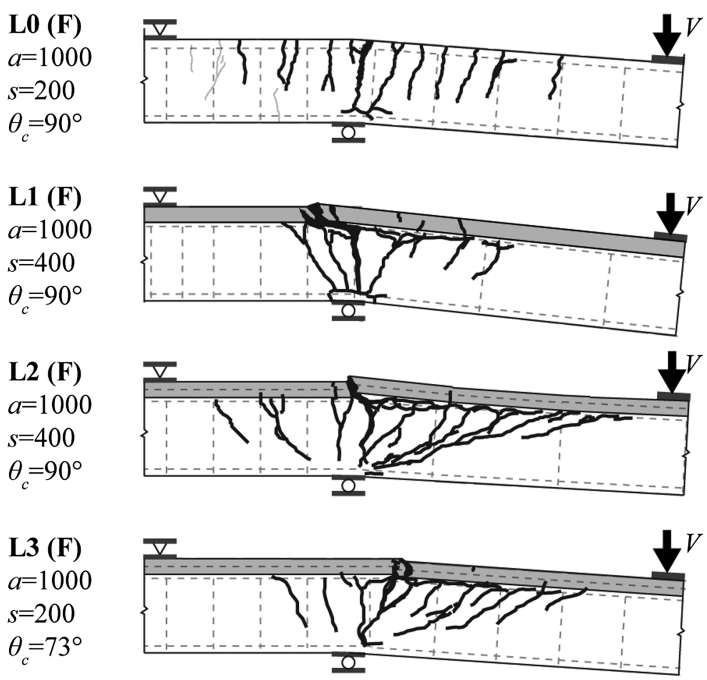

(a)
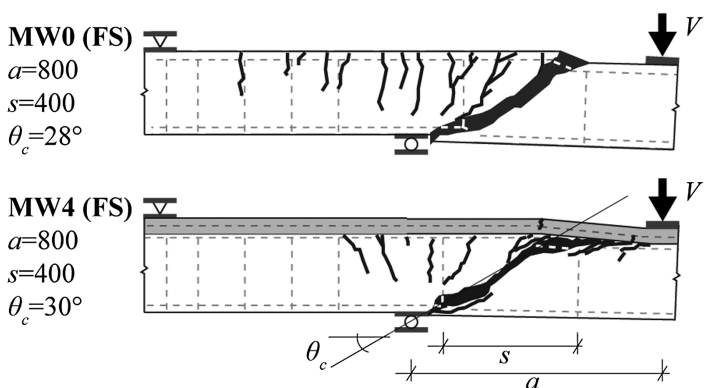

(b)
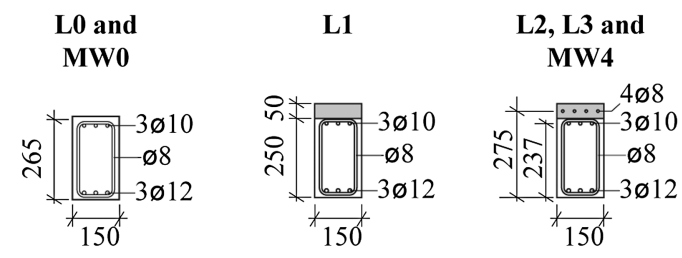

(c)

Dimensions in $\mathrm{mm}$

Fig. 8. Test specimens and final crack pattern; Note: $1 \mathrm{~mm}=$ 0.0394 in. (adapted from Noshiravani and Brühwiler 2013) 
Table 1. Material Properties (Noshirvani 2012)

\begin{tabular}{|c|c|c|c|c|c|c|}
\hline \multicolumn{7}{|c|}{ Concrete } \\
\hline$E_{c}(\mathrm{GPa})$ & \multicolumn{2}{|c|}{$f_{c, \text { cube }}(\mathrm{MPa})$} & \multicolumn{2}{|c|}{$f_{c}(\mathrm{MPa})$} & \multicolumn{2}{|c|}{$f_{c t}(\mathrm{MPa})$} \\
\hline 29.9 & \multicolumn{2}{|c|}{47.4} & \multicolumn{2}{|c|}{41.6} & \multicolumn{2}{|c|}{$2.30^{\mathrm{a}}$} \\
\hline \multicolumn{7}{|c|}{ UHPFRC } \\
\hline Specimen & $E_{U}(\mathrm{GPa})$ & $f_{U t, e l}(\mathrm{MPa})$ & $\epsilon_{U t, u}(\%)$ & $f_{U t, u}(\mathrm{MPa})$ & $w_{U, 1}, w_{\max }$ & $f_{U, 1}(\mathrm{MPa})$ \\
\hline Average & 48 & 10.2 & 0.3 & 12.5 & $2 \mathrm{~mm}, 6.50 \mathrm{~mm}$ & 3 \\
\hline L1 & & 7 & 0.3 & 8 & & 2.5 \\
\hline L2 & & 10 & 0.3 & 16 & & 5 \\
\hline L3 & & 10 & 0.3 & 18 & & 5 \\
\hline MW4 & & 10 & 0.3 & 12 & $1.5 \mathrm{~mm}, 6.5 \mathrm{~mm}$ & 3 \\
\hline \multicolumn{7}{|c|}{ Steel } \\
\hline Steel grade & $\phi(\mathrm{mm})$ & $E_{s}(\mathrm{GPa})$ & $f_{s y}(\mathrm{MPa})$ & $\epsilon_{s u}(\%)$ & $f_{s u}(\mathrm{MPa})$ & $f_{s u} / f_{s y}$ \\
\hline $\mathrm{B} 500 \mathrm{~B}^{\mathrm{b}}$ & 8 & 210 & 516 & 4.90 & 589 & 1.14 \\
\hline $\operatorname{Inox}^{\mathrm{c}}$ & 8 & & 710 & 2.20 & 906 & 1.27 \\
\hline B500 B & 10 & & 574 & 4.40 & 640 & 1.11 \\
\hline B500 B & 12 & & 574 & 4.40 & 640 & 1.11 \\
\hline B500 B & 14 & & 574 & 4.40 & 640 & 1.11 \\
\hline
\end{tabular}

Note: $1 \mathrm{Gpa}=1,000 \mathrm{Mpa}=145.0 \mathrm{ksi} ; 1 \mathrm{~mm}=0.0394 \mathrm{in}$.

${ }^{\mathrm{a}}$ Calculated value based on $f_{c}$.

${ }^{\mathrm{b}}$ Reinforcing bars used in the R-UHPFRC element of beam MW4 and as stirrups.

${ }^{\mathrm{c}} \mathrm{R}$-UHPFRC reinforcing bars in beams $\mathrm{L} 2$ and $\mathrm{L} 3$.

the failure mode that is either flexural (F) or flexure-shear (FS). Except for the stirrup spacing $(s)$ in the cantilever span, the RC elements have similar reinforcement. Fig. 8 also provides the measured angle of the collapse crack $\left(\theta_{c}\right)$.

Table 1 lists the average material properties of concrete, UHPFRC and steel reinforcing bars. Furthermore, it provides the estimated values of strength and crack opening for the tensile constitutive law of UHPFRC used in the FCH model for specific beams. These values are according to the range of results from UHPFRC direct tensile tests (Oesterlee 2010).

\section{Experimental versus Theoretical Member Response}

Fig. 9 provides the plots of the measured and calculated forcedeflection response of the specimens. The calculation uses a MATLAB program based on the FCH model in Fig. 6 (in)

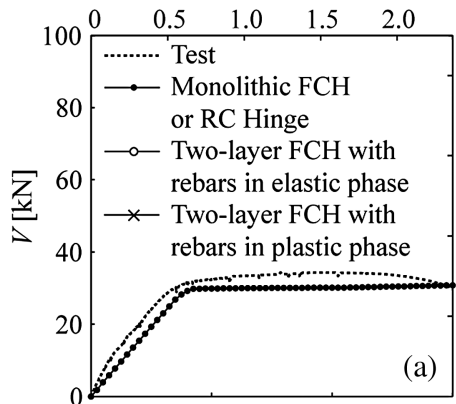

(a)

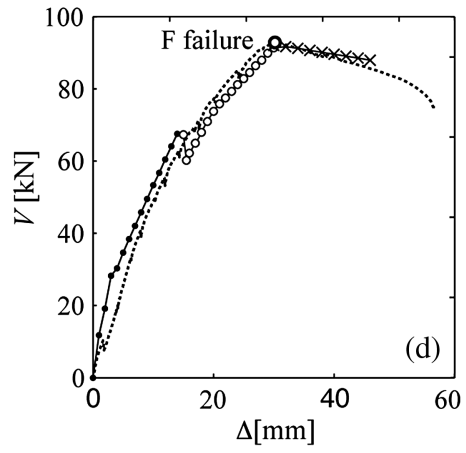

(in)

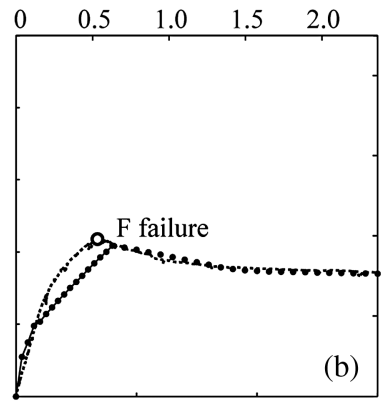

(b)

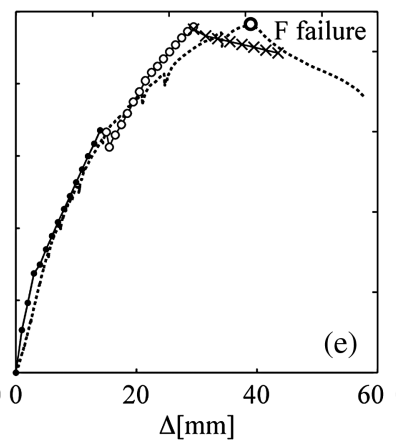

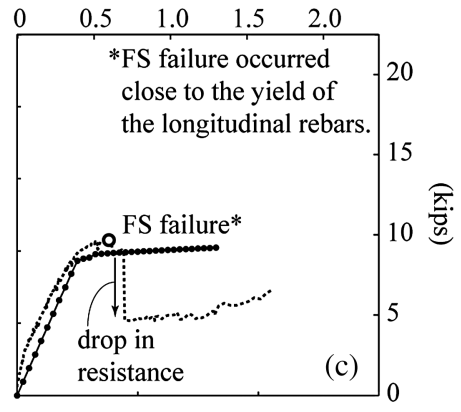

(in)

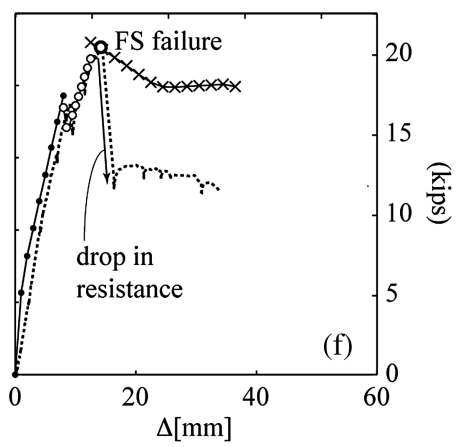

Fig. 9. Force-deflection response from experiments versus FCH model: (a) L0; (b) L1; (c) MW0; (d) L3; (e) L2; (f) MW4 


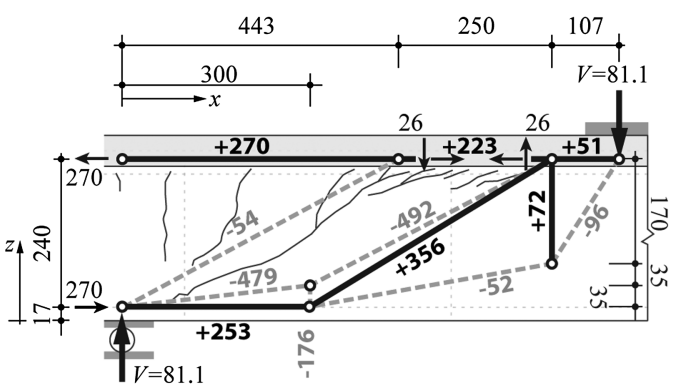

Units: Forces in kN; Dimensions in mm

(a)

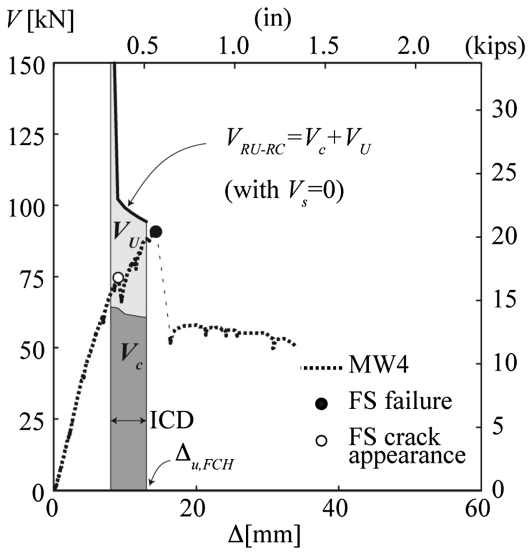

(b)

Fig. 10. Beam MW4: (a) Truss model at $V=81.1 \mathrm{kN}(18.2 \mathrm{kips}) ;$ (b) force-deflection versus shear strength curve; $1 \mathrm{kN}=0.224 \mathrm{kips} ; 1 \mathrm{~mm}=$ 0.039 in.

(Noshiravani 2012). The plots of the calculated response indicate the three states of the model of the monolithic beam, two-layer beam with reinforcing bars in the elastic state and the twolayer beam with reinforcing bars in the plastic state. There is a good agreement between the theoretical and the experimental forcedeflection response.

The value of $V_{\text {ICD }}$ is based on the observed formation of diagonal cracks in each tested specimen. In Beams MW0 and L2, the diagonal cracks are formed gradually as the flexural cracks rotate towards the intermediate support. The flexure-shear cracks in Beams MW4 and L3 appear suddenly at a force of $74.6 \mathrm{kN}$ (16.7 kips) and $71.0 \mathrm{kN}$ (15.9 kips), respectively. The observed cracking behavior is attributed to the high ratio of longitudinal reinforcement of the latter beams and wide stirrup spacing in the shear span. From Eq. (2), for an average crack spacing of $s_{m}=200 \mathrm{~mm}$ (7.87 in.), the calculated value of $V_{\text {ICD }}$ is $69.0 \mathrm{kN}$ (15.5 kips).

The crack patterns of Beams L2 and L3 show a series of flat cracks along the entire length of the beam that cause partial debonding of the two elements. According to the test results, the appearance of these cracks in Beam L2 is close to a jack force of $71 \mathrm{kN}$ (15.9 kips) on the ascending branch of the forcedisplacement response. The cracks in Beam L3 appear between a force of $71.3 \mathrm{kN}$ (16.0 kips) and $85.1 \mathrm{kN}$ (19.1 kips). $\theta_{\mathrm{ICD}}$ of $60^{\circ}$ and $35^{\circ}$ for the models of Beams L3 and L2 were chosen based the beams' crack pattern.

The contribution of the R-UHPFRC element to the member shear resistance can be demonstrated using the example of Beam MW4 with a discrete flexure-shear crack crossing no stirrup. The truss model in Fig. 10(a) describes the flow of forces in Beam MW4 after the appearance of the flexure-shear crack at a measured deflection of $11.4 \mathrm{~mm}$ (0.449 in.) and a jack force of $81.1 \mathrm{kN}$ (18.2 kips).

The calculated change in the force of the composite tension chord between State II and III regions is estimated as $47 \mathrm{kN}$ (10.5 kips). The tension member along the ICD zone is assumed to contain the full length of the R-UHPFRC hinge at the crack mouth and half of the length of the R-UHPFRC hinge between States II and III; thus, the truss member length is $250 \mathrm{~mm}$ (9.84 in.). Given the angle of the strut in State II, the shear force in the R-UHPFRC element is $26 \mathrm{kN}$ (5.82 kips). Close to the crack tip, stresses are resisted by both concrete and the compressive steel reinforcing bars. The calculated moment corresponding to the shear force in the layer is $3,250 \mathrm{kN}-\mathrm{mm}$ (2.39 kip-ft).

Fig. 10(b) shows the failure envelope of the RU-RC member as the sum of the contributions of concrete carrying the compressive stresses in front of the tip of the flexure-shear collapse crack and the R-UHPFRC element in double curvature. At the initial point, the length of the R-UHPFRC double hinge mechanism is at a minimum of $50 \mathrm{~mm}$ (1.97 in.). The end of the envelope corresponds to the end of the elastic phase of the model at a deflection of $\Delta_{u, \mathrm{FCH}}=13 \mathrm{~mm}$ (0.512 in.) and $V_{R U-R C}=94.2 \mathrm{KN}$ (21.1 kips). The plots show that the force-displacement response of the beam and the failure envelope approach each other close to the ultimate resistance of the beam. At its ultimate resistance, the force $V_{u}$ and deflection $\Delta_{u}$ of the beam are respectively 96 percent and 110 percent of the calculated failure criterion.

\section{Conclusions}

The presented model provides a rational method for the analysis of RU-RC beams enabling a refined analytical investigation of the structural response, rotation capacity and moment redistribution of RU-RC beams. The challenge in modeling the behavior of RU-RC beams is the multitude of nonlinearities in the system related to the materials and their interaction. The following conclusions are drawn:

1. The tension chord in RU-RC beams consists of the RC tension chord and the R-UHPFRC element. The contribution of the R-UHPFRC element significantly increases the member resistance.

2. A flexure-shear crack in the RC element initiates ICD and activates the bending action of the R-UHPFRC element.

3. By considering the state of cracks in the $\mathrm{RC}$ element and the deformations in the composite tension chord, the elasticplastic FCH model can determine the member response under combined bending and shear. To decouple the tension chord, the FCH model considers different hinge lengths for the RC reinforcing bars and the R-UHPFRC element and accounts for the relative displacement between the two elements along the ICD zone. The predictions of the model closely match the available experimental results.

4. The maximum resistance of the RU-RC member subjected to combined bending and shear is the sum of the contributions 
of the RC and the R-UHPFRC elements. The R-UHPFRC element contributes by bending in double curvature.

\section{Notation}

The following symbols are used in this paper:

$A=$ area;

$a=$ cantilever or shear span;

$b=$ width of beam section;

$C=$ compression force;

$c=$ height of neutral axis from extreme compression fiber in concrete $\left(C_{U}\right.$ in ultrahigh performance fiber reinforced concrete);

$d=$ depth measured from extreme compression fiber (without subscript it stands for effective depth of section);

$E=$ modulus of elasticity of materials or their stiffness at given state;

$f=$ strength of materials at given state;

$h=$ height;

I, II, III = State I to III of cracking;

$i=$ counter for cracks;

$l=$ length;

$M=$ moment;

$s=$ stirrup spacing (without subscript); $s_{m}$ refers to average crack spacing;

$T=$ tension in either steel or concrete or reinforced ultrahigh performance fiber reinforced concrete-reinforced concrete composite tension chord;

$V=$ shear force;

$w=$ width or opening of cracks in concrete $(c)$ and ultrahigh performance fiber reinforced concrete $(U)$;

$x, y, z=$ longitudinal, out-of-plane, and vertical axes;

$\Delta$ = difference;

$\Delta=$ displacement (of beam at point load); $\Delta_{U}$ is displacement of reinforced ultrahigh performance fiber reinforced concrete layer;

$\Delta \varepsilon_{U}=$ strain difference between ultrahigh performance fiber reinforced concrete and concrete due to slip along intermediate crack-induced debonding zone;

$\varepsilon=$ strain;

$\theta=$ angle of concrete cracks or collapse crack in concrete with respect to longitudinal axis;

$\kappa=$ curvature;

$\Sigma=$ sum;

$\zeta=$ angle of compression strut from longitudinal axis;

$\tau=$ shear stress; and

$\psi=$ rotation .

\section{Subscripts}

$b=$ related to bond along reinforcing bars;

$c=$ concrete or related to concrete cylinder compressive strength $\left(f_{c}\right)$;

$c b=$ bottom concrete fiber;

$c e=$ effective compressive strength;

$c r=$ cracking;

$c t=$ concrete in tension;

$e=$ effective;

el $=$ elastic;

$F=$ related to flexural mechanism, collapse or failure;

$F S$ = related to flexure-shear mechanism, collapse or failure;

$h=$ hinge (typically reinforced ultrahigh performance fiber reinforced concrete-reinforced concrete hinge); $h U=$ reinforced ultrahigh performance fiber reinforced concrete hinge;

ICD = related to intermediate crack-induced debonding zone or initiation or process of intermediate crack-induced debonding;

$i=$ index variable for components of reinforced ultrahigh performance fiber reinforced concrete-reinforced concrete section (e.g., st), for cracks or hinges;

$k=$ index variable related to given force or load;

$m=$ mean;

$R=$ resistance;

$R U-R C=$ related to reinforced ultrahigh performance fiber reinforced concrete-reinforced concrete composite members or tension chord;

$s=$ steel material or reinforcing bars in reinforced concrete section;

$s U=$ steel reinforcing bars in reinforced ultrahigh performance fiber reinforced concrete section;

$s b=$ bottom layer of steel reinforcing bars in reinforced concrete section;

$s h=$ steel in strain hardening;

$s t=$ top layer of steel reinforcing bars in reinforced concrete section;

$s y=$ yielding of steel;

$U=$ ultrahigh performance fiber reinforced concrete material or reinforced ultrahigh performance fiber reinforced concrete layer or hinge;

$U 1, U 2=$ reinforced ultrahigh performance fiber reinforced concrete hinges 1 and 2 in double hinge mechanism respectively located at mouth of diagonal crack and away from diagonal crack;

$U C=$ related to connection between ultrahigh performance fiber reinforced concrete and concrete;

$U c=$ ultrahigh performance fiber reinforced concrete in compression;

$U h=$ ultrahigh performance fiber reinforced concrete in tensile strain hardening;

$U t=$ ultrahigh performance fiber reinforced concrete in tension;

$U t, S=$ ultrahigh performance fiber reinforced concrete in tensile stress softening;

$u=$ ultimate, maximum, or peak strength or resistance; and

$y=$ related to yield strength of reinforcing bars (e.g., $M_{y}$ ).

\section{References}

Alaee, F. J., and Karihaloo, B. L. (2003). "Retrofitting of reinforced concrete beams with CARDIFRC." J. Compos. Constr., 10.1061/(ASCE) 1090-0268(2003)7:3(174), 174-186.

Bachmann, H. (1967). "Zur plastizitätstheoretischen Berechnung statisch unbestimmter Stahlbetonbalken." Doctoral thesis, Eidgenössische Technische Hochschule Zürich, Zürich, Switzerland (in German).

Brühwiler, E., and Denarié, E. (2008). "Rehabilitation of concrete structures using ultra-high performance fibre reinforced concrete." Ultra high performance concrete (UHPC), Kassel, The Second Int. Symp. on Ultra High Performance Concrete, Kassel University Press, Kassel, Germany.

Collins, M. P., and Mitchell, D. (1997). Prestressed concrete structures, Response Publications, Toronto.

Casanova, P., and Rossi, P. (1997). "Analysis and design of steel fiberreinfroced concrete beams." ACI Struct. J., 94(5), 595-602.

Dilger, W. (1966). Veränderlichkeit der Biege- und Schubsteifigkeit bei Stahlbetontragwerken und ihr Einfluss auf Schnittkraftverteilung und Traglast bei statisch unbestimmter Lagerung, Wilhelm Ernst \& Sohn, Berlin (in German). 
Habel, K., Denarié, E., and Brühwiler, E. (2006). "Structural response of elements combining ultrahigh-performance fiber-reinforced concretes and reinforced concrete." J. Struct. Eng., 10.1061/(ASCE)0733-9445 (2006)132:11(1793), 1793-1800.

Kani, G. N. J. (1966). "Basic facts concerning shear failure." ACI J. Proc., 63(6), 675-692.

Marti, P., Alvarez, M., Kaufmann, W., and Sigrist, V. (1998). "Tension chord model for structural concrete." Struct. Eng. Int., 8(4), 287-298.

Marti, P., Pfyl, T., Sigrist, V., and Ulaga, T. (1999). "Harmonized test procedures for steel fiber-reinforced concrete." ACI Mater. J., 96(6), 676-686.

Muttoni, A. (2008). "Punching shear strength of reinforced concrete slabs without transverse reinforcement." ACI Struct. J., 105(4), 440-450.

Muttoni, A., and Schwartz, J. (1991). "Behaviour of beams and punching in slabs without shear reinforcement." Proc. of the IABSE Colloquium, International Association for Bridge and Structural Engineering, Zurich, Switzerland.

Ng, T., Htut, T. N. S., and Foster, S. J. (2012). "Fracture of steel fibre reinforced concrete - The unified variable engagement model." UNICIV Rep. No. R-460, May 2012, Univ. of New South Wales, Sydney, Australia.

Noshiravani, T., and Brühwiler, E. (2013). "Experimental investigation on R-UHPFRC - RC composite beams subjected to combined bending and shear." ACI Struct. J., 110(2), 1-12.

Noshiravani, T. (2012). "Structural response of R-UHPFRC - RC composite members subjected to combined bending and shear." Doctoral thesis, École Polytechnique Fédérale de Lausanne, Lausanne, Switzerland.
Oesterlee, C. (2010). "Structural response of reinforced UHPFRC and RC composite members." Doctoral thesis, École Polytechnique Fédérale de Lausanne, Lausanne, Switzerland.

Schlaich, J., Schäfer, K., and Jennewein, M. (1987). "Toward a consistent design of structural concrete." J. Prestressed Concr. Inst., 32(3), $74-150$.

Service d'études techniques des routes et autoroutes (SETRA) and Association Française de Génie Civil (AFGC) (2002). Béton fibrés à ultra-hautes performances, AFGC, Paris (in French).

Sigrist, V. (1995). "Zum Verformungsvermögen von Stahlbetonträgern." Doctoral thesis, ETHZ, Zürich, Switzerland (in German).

Specht, M., and Scholz, H. (1995). Ein durchgängiges Ingenieurmodell zur Bestimmung der Querkrafttragfähigkeit im Bruchzustand von Bauteilen aus Stahlbeton mit und ohne Vorspannung der Festigkeitsklassen C 12 bis C 115. Beuth, Berlin, Germany (in German).

Stang, H., and Li, V. C. (2004). "Classification of fibre reinforced cementitious materials for structural applications." 6th RILEM Symp. on FiberReinforced Concretes (FRC) - BEFIB 2004, RILEM, Bagneux, France, 197-218.

Stoffel, P. (2000). "Zur Beurteilung der Tragsicherheit bestehender Stahlbetonbauten." Doctoral thesis, ETHZ, Zürich, Switzerland (in German).

Teng, J. G., Smith, S. T., Yao, J., and Chen, J. F. (2003). "Intermediate crack-induced debonding in RC beams and slabs." Constr. Build. Mater., 17(6-7), 447-462.

Wuest, J. (2007). "Comportement structural des bétons de fibres ultra performants en traction dans des éléments composés." Doctoral thesis, École Polytechnique Fédérale de Lausanne, Lausanne, Switzerland (in French). 